\title{
Representação política e acesso aos recursos federais
}

\section{Marcos Otavio Bezerra}

\section{Introdução}

Um dos símbolos mais freqüentemente associados à política é o Congresso Nacional. ${ }^{1}$ Apesar das distinções em termos de suas funções, Senado e Câmara têm como pregorrativas a discussão, proposição de leis e fiscalização das ações do Poder Executivo. ${ }^{2}$ As atribuições dos parlamentares manifestam-se no cotidiano do Congresso por meio de um conjunto de tarefas: votações, debates nas Comissões Permanentes, discussões em plenário e investigações realizadas pelas Comissões Parlamentares de Inquérito $^{3}$, entre outras. Graças sobretudo à imprensa, esse é o lado mais visível do trabalho parlamentar e, com exceção dos períodos eleitorais —o "tempo da política" ${ }^{-}$da vida política.

Porém, as atividades a que se dedica uma parcela significativa dos parlamentares não se restringem àquelas a que sua imagem está mais diretamente vinculada e que constitui a face mais pública do trabalho parlamentar. ${ }^{5}$ Essas atividades e as condutas a ela associadas são trazidas à luz, no entanto, somente sob a condição de se assumir um ponto de vista não institucional a respeito da atuação parlamentar. Em graus diferentes — pois deputados e senadores ao contrário da imagem mais comum não constituem uma categoria homogênea ${ }^{6}$ - observa-se que os parlamentares mobilizam parte de suas energias para viabilizar o atendimento dos designados pleitos, isto é, pedidos de caráter particularísticos encaminhados sobretudo por prefeitos e lideranças políticas locais, relativos especialmente à obtenção de recursos federais. $\mathrm{O}$ reconhecimento da diferenciação interna dos deputados e senadores não elimina, todavia, o fato de que grande parte deles defronta e vê-se diante da necessidade de oferecer

Marcos Otavio
Bezerra é
professor do
Departamento
de Sociologia
da Universidade
Federal
Fluminense
(UFF),
pesquisador
do Núcleo de
Antropologia
da Política
(NuAP), mestre
e doutor em
antropologia
social pelo
PPGAS/MN/
UFRJ 
algum tipo de resposta, com os pedidos de caráter particularista e as expectativas de políticos locais concernentes à obtenção de recursos federais. Por conseguinte, um dos objetivos desse trabalho consiste em descrever e analisar as forças sociais e pressões exercidas sobre os parlamentares, e outros agentes a eles relacionados, em função da posição que ocupam no universo político focalizado.

Assegurar a liberação de recursos para os estados, regiões e municípios que representam é algo vivido por deputados e senadores como um dever parlamentar. Todavia, esse é um aspecto pouco acentuado de sua atuação. Constitui, por assim dizer, um lado mais invisível de seu trabalho político. O conjunto de relações, práticas e concepções produzidas em torno da atuação dos parlamentares orientado para a liberação de recursos federais para suas bases eleitorais é o tema central deste trabalho. Sustento a seguir que ao se dirigir o foco da análise para essa forma específica, mas não exclusiva, de atuação, é possível revelar e dar inteligibilidade a certas relações que estruturam o universo político brasileiro.

A destinação, por parte de políticos, de benefícios públicos (recursos, cargos, serviços e outros) para lideranças políticas e moradores das localidades, aos quais se encontram vinculados politicamente, é uma das principais questões examinadas pela literatura a respeito do clientelismo político. ${ }^{7}$ Embora correndo o risco de ser demasiado sucinto, observo que as relações de patronagem e clientelismo têm sido submetidas mais comumente a duas linhas de interpretação. Na primeira delas, em que predomina o ponto de vista das teorias modernizantes, essas relações são interpretadas como "tradicionais" e, por conseguinte, como uma espécie de "resquício" em vias de desaparecimento devido à expansão das relações impessoais, universais e racionais - representadas, por exemplo, pelo mercado, a burocracia estatal e a institucionalização das relações políticas. ${ }^{8}$ $\mathrm{Na}$ segunda linha de interpretação, as relações de patronagem e clientelismo têm sido consideradas como uma espécie de complemento, de adendum para utilizar o termo difundido por Landé (1977). Elas aparecem para cobrir lacunas (gaps) e falhas geradas pelo funcionamento inadequado das instituições sociais ou amenizar incertezas decorrentes seja da ausência, seja da presença das relações de mercado ou estatais. ${ }^{9}$ De qualquer forma, tendem ao desaparecimento num contexto imaginado como de pleno funcionamento dessas instituições.

O que parece comum a essas duas linhas de interpretação, entre outros aspectos, é o fato de atribuírem às relações de patronagem e clientelismo uma espécie de lugar secundário nas análises. Dito de outro modo, as relações e práticas que têm sido descritas sob a rubrica de clientelismo - os vínculos fundados na troca de favores, serviços e apoio, as exigências de lealdade e os compromissos políticos, por exemplo — não são tratadas como fenômenos que detêm um estatuto sociológico 
próprio. Não são consideradas propriamente como ordenadoras das relações políticas. ${ }^{10} \mathrm{O}$ aspecto secundário atribuído a essas relações parece decorrer, entre outros elementos, do pressuposto, que não parece se sustentar, de que a política, sobretudo a política oficial (estatal), se faz, exclusiva ou predominantemente, por meio dos canais e instituições oficiais do sistema político (partidos, eleições, Congresso) que, ademais, se supõe que funcione segundo o modelo formal enunciado pelas regras oficiais. Assim, ao se destacar, por exemplo, o lado funcional dessas relações, como a de suprir falhas, minimiza-se o que me parece ser um de seus aspectos sociológicos importantes, ou seja, a dimensão estruturante das relações sociais. ${ }^{11}$

Para resgatar esse lado positivo das relações descritas em termos de clientelismo, um passo necessário é que se esteja atento para o modo como, ao mesmo tempo, as trocas conformam e são conformadas pelas relações sociais. Esse aspecto, examinado exemplarmente por Mauss (1974), não deixou de ser explorado pela literatura sobre patronagem e clientelismo (Pitt-Rivers, 1971, Foster, 1967 e Wolf, 1966, por exemplo). Contudo, essa dimensão do fenômeno das trocas tem sido minimizada em análises efetuadas sobre o clientelismo político. Como sugerido acima, essas análises têm dado destaque à idéia de que o clientelismo implica troca de benefícios públicos por apoio político e votos. Se o cálculo político-eleitoral é um dos elementos dessa relação, ele, entretanto, não é o único presente. $\mathrm{O}$ fato, por exemplo, da troca de benefícios e apoio (ou votos) constituir um momento de uma relação mais ampla entre os atores envolvidos ou instituir obrigações morais entre eles não são aspectos considerados. De modo geral, o que parece evidente é que predomina uma perspectiva, reducionista a meu ver, que tende a mercantilizar essas trocas. Elas são tratadas de modo mecânico, utilitarista e tornam-se uma espécie de "toma-lá-dá-cá" que pode ser resumido na fórmula: benefícios públicos são retribuídos com votos. Mais do que algo a ser explicado, portanto, a noção de troca torna-se um princípio explicativo, uma espécie de camisa de força, ao qual são subordinadas as relações e práticas sociais observadas.

Neste caso, a dimensão propriamente sociológica dessas trocas é deixada de lado. Assim, as mediações necessárias para que os benefícios sejam concedidos, e os votos obtidos, não chegam a ser examinadas. Entre outros aspectos, não são integrados à análise o intervalo de tempo existente entre a concessão dos favores ou benefício público e os votos e as práticas - como as que são responsáveis pela demonstração de interesse na continuidade da relação (correspondências, pequenos favores, visitas etc.) - que se interpõem entre esses atos. ${ }^{12}$ Some-se a isso o fato de que ao se dar ênfase à troca de benefícios públicos por apoio e voto, ignora-se que a mesma ocorre num contexto complexo 
onde estão em jogo, por exemplo, a busca de prestígio, poder e o cumprimento de obrigações formais e morais.

Ao focalizar a atuação dos parlamentares em favor da liberação de recursos para suas bases, argumento que: 1) ao se considerar mais detidamente o que está em jogo nessa forma de atuação dos parlamentares, percebe-se que ela remete a uma concepção específica (pode-se dizer nativa) da representação política que se afasta das formulações clássicas elaboradas pelos filósofos políticos; o que, a meu ver, impõe limites para a interpretação das relações dos parlamentares com suas bases em termos somente das relações de clientelismo; 2) é somente no contexto das relações estabelecidas pelos parlamentares com lideranças políticas locais (como prefeitos), autoridades governamentais e agentes privados (como escritórios de consultoria e empreiteiras) é que essa forma de atuação torna-se inteligível; 3) a atuação dos parlamentares referida a essa espécie de ética fundada na ligação às bases torna pouco nítidas e fluidas as fronteiras que separam o legal do ilegal.

A seguir, examino alguns aspectos relativos à atuação dos parlamentares na elaboração do orçamento para, em seguida, descrever a dinâmica das relações dos parlamentares com os políticos locais e autoridades do Executivo e, enfim, mostrar a articulação existente entre as condutas políticas, tidas como legítimas, e práticas socialmente percebidas como corruptas.

\section{A luta por recursos e a elaboração do orçamento da União}

Com a promulgação da Constituição de 1988, os parlamentares recuperam a prerrogativa de intervirem na elaboração do orçamento. Os recursos federais passíveis de serem transferidos para os municípios - excluídas as transferências obrigatórias que são definidas constitucionalmente - são aqueles incluídos na parcela destinada aos investimentos. Nos últimos anos, essa parcela tem variado em torno dos $2 \%$ do total dos recursos orçamentários. ${ }^{13}$ De modo geral, o acesso dos políticos locais a esses recursos ocorre por dois caminhos. Primeiro, via emendas orçamentárias dos parlamentares. ${ }^{14}$ Segundo, via programas desenvolvidos pelos ministérios por meio da utilização das designadas dotações globais, isto é, recursos cuja destinação é autorizada pelo ministro da pasta. Todavia, como a Lei Orçamentária possui caráter apenas autorizativo, deve-se observar que a decisão final a respeito da liberação dos recursos cabe ao Poder Executivo.

Quando se examina a intervenção dos parlamentares nas diversas etapas de elaboração do orçamento, observa-se que, de modo geral, 
prevalece a preocupação dos mesmos com a destinação de recursos para os municípios e regiões aos quais estão politicamente vinculados. ${ }^{15}$ A apresentação de emendas ao orçamento da União constitui para o parlamentar o caminho institucional por meio do qual ele pode buscar atender aos pedidos de investimentos e verbas encaminhados pelos prefeitos. Por conseguinte, o momento de elaboração das emendas e de sua apresentação à Comissão Mista de Planos, Orçamentos Públicos e Fiscalização (CMPOF) é estratégico para as relações do parlamentar com as lideranças locais, pois suas decisões repercutem diretamente em sua rede de relações políticas. À capacidade do parlamentar de aprovar e, posteriormente, liberar os recursos, estão associadas, por exemplo, sua reputação e chances eleitorais.

Do ponto de vista legal, nada impede que o parlamentar, por meio de suas emendas individuais, destine recursos para estados ou municípios pelos quais ele não foi eleito. No entanto, essa é uma prática pouco comum. Quando isso ocorre, e é levado ao conhecimento público, o parlamentar é freqüentemente alvo de suspeitas ou acusações por parte de seus pares e da imprensa: suspeita de corrupção por estar favorecendo empresas que realizam obras em outros estados ou acusações de estar destinando recursos federais para outras regiões em detrimento do próprio estado e municípios pelo qual o parlamentar é eleito. O que se observa é que as denúncias dirigidas aos parlamentares que beneficiam outros estados acabam operando como uma espécie de coerção a mais, que faz com que deputados e senadores elaborem suas emendas de modo a que atendam aos interesses ligados aos estados e municípios pelos quais se elegem.

Se a inserção na política nacional introduz um distanciamento em relação à política estadual e municipal — o que pode ser visto como algo negativo por seus eleitores e lideranças locais na medida em que o parlamentar parece menos disponível para resolução de seus problemas imediatos ${ }^{16}$ — um meio de minimizá-lo é por meio do atendimento dos pleitos de verbas encaminhados pelas lideranças locais. Assim, deixar de atender a essas demandas pode aumentar ainda mais esse afastamento na medida em que resulta num duplo distanciamento das bases eleitorais: o afastamento físico e o afastamento das atribuições que lhes são associadas - o que, por sua vez, aumenta o espaço para que políticos concorrentes realizem seu próprio trabalho na base do parlamentar. A preocupação com a manutenção desses laços é, ademais, um exemplo de como a relação dos parlamentares com suas bases não pode ser entendida somente a partir de uma referência à questão da obtenção de votos.

Um dos efeitos desse interesse em beneficiar os estados e municípios que representam é a introdução e a legitimação — no plano da elaboração e execução do orçamento da União — da concorrência 
entre os parlamentares pela liberação das verbas federais. Por conseguinte, olhando da perspectiva do orçamento e da natureza da intervenção parlamentar, o governo federal aparece recortado por distintos e concorrentes interesses locais. Enfim, esta forma de atuação dos parlamentares pode ser vista como um exemplo do modo como a "redistribuição burocrática" sujeita-se às apropriações pessoais e clientelistas (Bourdieu, 1996a:16).

\section{A interdependência entre parlamentares e lideranças políticas locais}

O interesse dos parlamentares em obter recursos federais para suas bases eleitorais e sua atuação nos órgãos ministeriais para que os recursos sejam efetivamente liberados são melhor compreendidos quando examinados no contexto das relações de dependência mútua e assimétrica que vinculam os parlamentares, por um lado, às lideranças políticas locais $\mathrm{e}$, por outro, às autoridades governamentais.

Como observou M. Weber, ao lado do Direito, da convenção e do costume, o interesse das pessoas opera como uma garantia de continuidade de uma determinada conduta consensual (1984: 267). Assim, a disposição de deputados e senadores para atender aos pleitos das lideranças políticas de suas bases eleitorais está relacionada, entre outros aspectos, às expectativas que essas lideranças possuem em relação aos parlamentares.

Em linhas gerais, fora dos períodos eleitorais, os prefeitos esperam dos parlamentares que estes realizem pequenos favores, encaminhem seus interesses junto à burocracia governamental e, principalmente, obtenham verbas federais para a realização de investimentos nos municípios.

Compreende-se melhor o interesse dos prefeitos em torno da obtenção das verbas federais quando se considera o valor que é atribuído, pelos políticos e pela população, à realização de obras públicas. $\mathrm{O}$ vínculo estreito existente entre "fazer política" e realizar obras é ressaltado por M. Palmeira ao sugerir, a partir de estudo realizado junto à populações rurais no Estado de Pernambuco, que "as obras são a face pública da política" (1998:11). Às obras públicas estão associadas, por exemplo, a reputação do político e uma concepção prática sobre a política. A importância atribuída às obras

ajuda a entender ainda como se dá a articulação das empreiteiras com o universo político e por meio de que atividades elas se fazem presentes nos órgãos públicos (municipais, estaduais e federais).

Parte da força do parlamentar, frente aos prefeitos, reside na possibilidade que o primeiro possui de viabilizar o acesso destes últimos às autoridades governamentais. Para o prefeito, o acesso aos ministros é ao 
mesmo tempo um indicador de seu prestígio e do prestígio do parlamentar que propiciou a audiência, ou seja, uma demonstração — para a população e seus concorrentes - de seu poder pessoal. $\mathrm{O}$ registro desses encontros (os prefeitos freqüentemente tiram fotos com os ministros) e a sua divulgação por meio da publicação em jornais locais mostram que a ligação com altas esferas do poder político tem para o parlamentar e para o prefeito um efeito positivo junto às suas bases eleitorais. É uma demonstração, em último caso, da força e eficácia de suas ligações. ${ }^{17}$

Para encaminhar seus pleitos, o prefeito procura preferencialmente o parlamentar a quem deu apoio nas eleições ou aquele que obteve maior votação no município. Se é junto a este que o prefeito tem mais força, é com freqüência, contudo, que os pedidos são encaminhados a mais de um parlamentar. Distintamente das situações clássicas descritas pela literatura sobre patronagem e clientelismo — nas quais é ressaltada a relação de exclusividade entre patrão e cliente — os prefeitos jogam eventualmente com os diversos contatos disponíveis. Observe-se, ademais, que tanto a relação dos parlamentares com os prefeitos, quanto a relação dos parlamentares entre si, sobretudo os que pertencem ao mesmo estado, está relacionada à concorrência entre esses últimos pela obtenção do apoio dos prefeitos. Em certas circunstâncias, esta busca de apoio toma a forma de uma concorrência em termos de generosidade (hospedar, buscar no aeroporto em Brasília, tratar com gentileza etc.).

Cabe observar, no entanto, que recorrer ao parlamentar a quem se deu apoio ou àquele que foi mais votado no município nem sempre é o melhor caminho para se ter um pleito atendido, sobretudo no caso de liberação de recursos, uma vez que esse parlamentar pode defender posições contrárias aos interesses do governo. O parlamentar com maior chance de liberar recursos, observa um deputado (PMDB-ES), "é aquele que manda a cartilha do governo, ou seja, é aquele deputado chamado deputado governista, aquele que está dentro do partido do governo, os partidos que apóiam o governo”. São os parlamentares que apóiam o governo os que têm maior probabilidade de terem seus pedidos atendidos.

Ao se considerar os critérios que parlamentares e assessores dizem utilizar para definir para quais municípios e programas serão destinadas as emendas, destaca-se a votação obtida pelo parlamentar nas eleições anteriores. A votação no município cria, segundo a lógica das dívidas e créditos pessoais (Mauss, 1974 e Leach, 1989) um laço entre o parlamentar e as lideranças que o apóiam. A idéia de responsabilidade que o parlamentar afirma ter em relação a esses municípios onde obteve votação, parece expressar o sentimento de obrigação que o mesmo experimenta em relação àqueles que lhe ajudaram. A intervenção no orçamento é, assim, um momento de retribuição pelo apoio concedido, apesar da relação não se 
esgotar em compromissos eleitorais, uma forma de realimentar a relação e atender às expectativas relacionadas à função.

O trabalho dos parlamentares em torno do atendimento desses pedidos é desenvolvido para que tenham o domínio das lideranças locais por meio da criação de dívidas morais, ou seja, é uma forma de estabelecimento de vínculos de dominação pessoal (Bourdieu, 1976). Assim, a mediação dos pedidos é um meio de se obter os votos e o apoio político de eleitores e lideranças políticas tendo, primeiramente, as pessoas por meio dos favores. É nesse contexto de dívidas e créditos pessoais que se inscreve a relação dos parlamentares com as lideranças políticas locais. E, ao contrário do que ocorre com as questões legislativas, parlamentares e seus assessores crêem que é este trabalho em torno dos pedidos que traz votos. E como demonstrou Mauss (1974a) ao discutir a magia, se é efetivamente esse trabalho o responsável pela eleição ou não dos candidatos, essa é uma questão menor diante da crença de que é isso efetivamente o que ocorre e das práticas que a crença desencadeia.

Ao viabilizar o atendimento de um pleito, o parlamentar, ao mesmo tempo, investe na continuidade da relação e renova os compromissos políticos existentes. A atualização dos vínculos está associada à própria natureza do compromisso estabelecido entre parlamentar e lideranças locais. Discutindo o "compromisso coronelista", Victor N. Leal nos fornece uma pista para entender a necessidade dessa constante renovação. Segundo esse autor, os vínculos, no caso entre as lideranças políticas locais e a situação estadual, são geralmente momentâneos visto que são firmados não "à base de princípios políticos, mas em torno de coisas concretas, prevalecem para uma ou para poucas eleições próximas" (1975: 41). O fato de estarem fundados em torno de demandas concretas torna esses vínculos frágeis e sujeitos às oscilações em torno da capacidade de prefeitos e parlamentares de atenderem aos interesses mútuos. ${ }^{18}$ Isso faz com que esses vínculos precisem ser renovados com freqüência. A natureza dessas relações — que parecem se manter em uma espécie de equilíbrio instável — ajuda a entender ainda a mobilidade dos políticos pelas facções e partidos.

A expectativa do parlamentar, por sua vez, é que os favores prestados e os recursos liberados contribuam para a consolidação de sua reputação e sejam retribuídos sob a forma de apoio político em suas futuras candidaturas. Se os prefeitos dependem dos parlamentares para obterem recursos federais, a necessidade de obter o apoio dos prefeitos coloca o parlamentar numa posição de dependência em relação a estes e dá aos prefeitos uma força relativa frente ao parlamentar.

Apesar da distância histórica e sociológica que separa as eleições atuais das eleições realizadas em Roma no século V a.C., a questão em 
jogo na atuação dos parlamentares parece ser aquela mencionada por

M. I. Finley ao observar que "o êxito eleitoral, em Roma, exigia que fosse cultivada a amizade de indivíduos decisivos em cada tribo, os quais estavam em posição de apresentar eleitores bastantes para garantir o voto unitário da tribo" (1985: 64). A relação dos parlamentares com as personalidades locais notáveis é destacada também por Weber ao referir-se - tratando do caso francês — àqueles que os primeiros recorrem quando desejam se reeleger: "Para ser reeleito, o deputado, por sua vez, mantinha ligações com os notáveis locais" (1982: 124). O cultivo das relações com os oligarcas e as lideranças locais como condição para a ascensão política e a vitória nas eleições no Brasil foram também destacados, entre outros, por Graham e Leal, (1975) respectivamente, para o Império e a Primeira República. Como sugere o primeiro ao discutir o significado das eleições, "a medida de um homem dependia do tamanho de seu grupo de seguidores" (1997: 112).

São as lideranças locais que asseguram a participação política dos parlamentares nos municípios e suas votações. Da perspectiva eleitoral, o apoio político do prefeito é, portanto, essencial para uma parcela significativa dos parlamentares. Observe-se a formulação efetuada por um senador (PMDB-PB) a respeito das ligações entre prefeitos, parlamentares e a estrutura política do parlamentar: "O município é a base política de qualquer parlamentar, se o município não quiser atendê-lo, toda a estrutura política estará deficitária. Então, a gente tem que começar a ter o apoio do prefeito e do município". Apesar da legislação assegurar ao parlamentar o direito de ser eleito em todo o estado, o que opera na prática, como tem sido apontado por vários autores, é uma forma de distritalização do voto. É por meio do apoio dos prefeitos e lideranças políticas locais que os parlamentares montam e expandem suas redes políticas pelos municípios.

Para o parlamentar, o poder do prefeito resulta, entre outros aspectos, do controle sobre a administração municipal e seu prestígio político no município, isto é, em última instância, do apoio que é capaz de lhe proporcionar por meio da mobilização dos membros locais de suas redes políticas e de seus pedidos de votos para o candidato. Porém, a força de lideranças políticas locais manifesta-se ainda no fato de que elas exercem um controle sobre a presença dos candidatos nos municípios. As chances destes últimos desenvolverem suas campanhas e obterem votos no município dependem do apoio concedido por essas lideranças. O vínculo com essas lideranças constitui, inclusive, uma condição para a entrada dos parlamentares nos municípios. Apesar de as análises destacarem mais frequientemente a dependência das lideranças municipais em relação ao poder central, essa dependência dos políticos 
federais e estaduais em relação às lideranças locais é ressaltada, entre outros, por Leal (1975), Queiroz (1976) e Graham (1997).

\section{A interdependência entre parlamentares e governo}

Para que os favores sejam realizados e, sobretudo, para que os recursos federais sejam liberados é essencial que parlamentares intervenham nos órgãos ministeriais. Isso é feito sobretudo por meio dos pedidos políticos (pleitos) dos parlamentares. A realização desses pedidos é considerada por parlamentares e autoridades governamentais como uma prática rotineira e geral. ${ }^{19}$ Os pedidos são tidos como o lado político da liberação dos recursos federais.

As pressões exercidas nos ministérios são concebidas como algo legítimo politicamente. Fazem parte da luta pela transferência de recursos federais. Dispostos a liberar os recursos, os parlamentares recorrem a todos aqueles que em função de suas posições institucionais, vínculos sociais e prestígio podem de algum modo contribuir para que isso se efetue.

$\mathrm{O}$ efeito do pedido de um parlamentar - que varia em função de aspectos como o prestígio de quem pede, a sua relação com o ministro e o poder de retaliação sobre o órgão - sobre o trâmite de um processo ou a liberação de recursos foi destacado pelo coordenador-geral de um órgão ministerial. $\mathrm{O}$ interessante, do ponto de vista da análise, é que as considerações do coordenador expressam a perspectiva de alguém que possui uma visão do interior do órgão. Como se trata de uma prática rotineira, o coordenador reconheceu que, estando um processo dentro das normas, um pedido tanto agiliza o processo quanto atribui à solicitação de um prefeito ou entidade um peso maior. $\mathrm{O}$ poder efetivo do parlamentar reside na capacidade de fazer com que as solicitações sejam, em termos nativos, agilizadas e priorizadas na burocracia governamental. Esses aspectos (a agilização e priorização) são considerados como a parte política do processo. Como sugeriu, chamando atenção para o que se concebe como o exercício da política no cotidiano, isto é política.

A questão do acesso às instituições e pessoas como fonte de poder social é abordada pela literatura voltada para a discussão das intermediações e mediações sociais. ${ }^{20}$ Esse acesso - sustentado por propriedades sociais distintas como status, poder econômico e político, domínio da escrita e de regras de conduta e contatos com pessoas que desempenham funções em órgãos públicos ou instituições privadas - qualifica socialmente certas pessoas para o exercício da mediação. Quando se reflete sobre a relação que mantêm as pessoas com o poder público, o acesso às autoridades e funcionários é um elemento que diferencia o cidadão comum do 
parlamentar. Notadamente quando se trata dos órgãos ministeriais, o acesso aos ministros, por exemplo, é algo quase impossível para os primeiros e mesmo para pessoas que desempenham funções públicas, como os prefeitos. Essa dificuldade é amenizada, contudo, se o contato é mediado pelo parlamentar. Como observa um deputado (PFL-PE): “A diferença é mais no acesso, quer dizer, o cara quer falar com o ministro, ele não consegue, se ele for com o parlamentar, ele consegue. (...) Normalmente ele consegue colocar o pleito dele, aí se consegue ter uma chance de resolver, mas se você não consegue não tem chance nenhuma". Se o pedido pessoal ao ministro é o que aumenta efetivamente as chances de um pleito ser atendido, isso acaba valorizando as mediações que são realizadas para que o contato seja estabelecido. Logo, é nessa possibilidade de fazer com que os pleitos recebam um tratamento prioritário nos órgãos ministeriais que reside, ao menos em parte, a força social do parlamentar junto à sua rede política. $\mathrm{O}$ acesso aos órgãos governamentais torna-se fonte de poder social. Essa autoridade dos deputados e senadores é reforçada pelos próprios órgãos ministeriais na medida em que reconhecem, em função de seus interesses específicos, que os mesmos merecem ser atendidos e ouvidos.

O parlamentar ideal para encaminhar esse tipo de pedido é aquele que pode beneficiar-se politicamente da realização do empreendimento, ou seja, um parlamentar que tenha sua base eleitoral na região ou município onde é executada a obra. Isso atende aos próprios interesses políticos do parlamentar na localidade, na medida em que pode apresentar a obra como fruto de seu trabalho.

A prioridade concedida ao atendimento dos pleitos dos deputados e senadores governistas, isto é, que apóiam o governo em suas iniciativas, é um princípio de atuação que o governo procura pôr em prática. Isso é o que informa, por exemplo, um deputado (PFL-PE): "Teoricamente é para ser o seguinte: os partidos que apóiam o governo, eles deveriam ter mais facilidade em resolver as coisas". Esse princípio de atuação do Poder Executivo e o efeito que isso produz em termos de configuração política, ou seja, a aproximação das lideranças políticas dos partidos ou grupos que têm o controle do Poder Executivo é um fenômeno descrito por autores que analisaram a história política do Brasil. Referindo-se às relações entre os chefes políticos municipais e o governo estadual durante a Primeira República, Leal (1975) designou como "governismo" o movimento das lideranças políticas municipais no sentido de apoio à situação estadual. Assim como as nomeações para os cargos públicos, a liberação de recursos federais, segundo o critério de apoio ao governo, constitui um benefício do qual desfrutam aqueles que integram ou lhe concedem o seu apoio. A aplicação desse critério funciona como 
instrumento político (Ames, 1995 e Geddes e Neto, 1992) de construção, de maioria governamental.

Para que isso seja assegurado, o Poder Executivo mantém um sistema de informações sobre a atuação dos parlamentares (votação, discursos etc.) que opera como um instrumento de administração governamental. Além das medidas rotineiras de controle da administração pública, os ministros dispõem de relatórios atualizados a respeito do posicionamento dos parlamentares em relação ao governo. Essas são informações que permitem que os ministros e sua assessoria elaborem uma espécie de mapa da atuação dos parlamentares em termos de apoio às iniciativas do governo e do ministério. Mais do que um instrumento de controle administrativo, esses relatórios consistem em um instrumento tido como político. Um dos efeitos dessa preferência manifestada pelo Poder Executivo pelas demandas originadas de políticos que apóiam o governo é a aproximação das lideranças políticas locais e dos parlamentares dos partidos e grupos que têm o controle do governo.

Se o controle do governo sobre a execução orçamentária define o poder deste frente aos parlamentares, o voto do parlamentar no Congresso atribui poder a este em relação ao governo. A negociação, envolvendo os interesses de parlamentares e Executivo, é vista, tanto por pessoas posicionadas nos órgãos ministeriais, quanto do Legislativo, como uma troca, assentada na interdependência institucional dos poderes, que é percebida como política.

Em termos gerais, percebe-se que para parlamentares, assim como para funcionários e assessores do Executivo e Legislativo, a troca de apoio político por nomeações e recursos públicos constitui uma espécie de modelo nativo tanto para a prática quanto para a interpretação das relações instituídas entre parlamentares, lideranças políticas locais e governo.

Constata-se, enfim, que a prática de atendimento das demandas particularísticas por parte dos parlamentares, por um lado, e a aproximação destes últimos do governo, por outro, isto é, o que tem sido mais comumente descrito em termos, respectivamente, de clientelismo e governismo, são fenômenos sociais que se articulam e fomentam mutuamente.

\section{Sobre condutas políticas e práticas corruptas}

A atuação de parlamentares para atender aos pleitos que lhes são encaminhados e garantir a liberação de recursos para suas bases eleitorais está associada a um conjunto de práticas tidas como irregulares, tanto do ponto de vista legal quanto ético, como demonstram a criação da designada 
CPI do Orçamento e as denúncias publicadas pela imprensa durante a elaboração e votação do projeto de lei orçamentária.

No Brasil, os debates públicos sobre o fenômeno da corrupção têm privilegiado a dimensão individual e, por conseguinte, tratado a corrupção notadamente como um problema de desvio ético. Pouco se tem refletido, no entanto, a respeito do vínculo dessas práticas com as relações e práticas políticas e administrativas por meio das quais se faz legitimamente a política. ${ }^{21} \mathrm{O}$ que se percebe é que a corrupção não funciona, como observa Cartier-Bresson (1992), se não se apóia em objetivos mais amplos que o enriquecimento pessoal. Ao se examinar as práticas que têm sido designadas como corruptas no contexto das relações sociais estabelecidas entre parlamentares, prefeitos, autoridades governamentais e agentes privados, constata-se que a apropriação irregular de recursos públicos não ocorre de modo descolado — o que torna a situação bem mais complexa — da busca de prestígio, votos, apoio político, cumprimento dos compromissos pessoais e atendimento de obrigações e expectativas políticas por parte dos políticos.

As condutas políticas servem ao mesmo tempo como apoio e definem a forma de ação dos parlamentares, escritórios e empresas interessadas em terem acesso aos recursos federais. Um exemplo disso é o fato de empreiteiras se preocuparem com o laço regional dos parlamentares e prefeitos envolvidos na obtenção de recursos para obras de seu interesse, de buscar o apoio de parlamentares governistas e de atuar nas diferentes etapas de elaboração e execução do orçamento. Por conseguinte, o fato de os parlamentares, escritórios e empresas seguirem os trâmites formais e atenderem às exigências oficiais não impede que estes obtenham benefícios corruptos. Como sugeriu Scott (1969), esse talvez seja um bom exemplo do modo como a corrupção pode ocorrer, não no momento de elaboração das leis, mas de sua aplicação. $O$ fato de estar colada às condutas políticas e aos procedimentos administrativos assegura às práticas corruptas, inclusive, uma maior invisibilidade (Mény, 1992).

Do ponto de vista da relação entre a política local e a grande política é interessante destacar a importância dos escritórios e empresas como um elemento de ligação entre essas duas instâncias. Isso ocorre na medida em que são capazes de intervir nas distintas etapas e articular os vários interesses existentes em torno da liberação dos recursos.

Diferentemente do caso italiano, por exemplo, no qual a corrupção passa mais diretamente pela intermediação dos partidos políticos (Little e Posada-Carbó, 1996: 6), no caso do Brasil, o acesso aos recursos do Estado parece ser mediado mais freqüentemente por lideranças políticas locais e nacionais.

Enfim, resta ainda uma última observação a ser efetuada a respeito da relação entre os fenômenos do clientelismo e da corrupção. Como 
sugeriu Della Porta (1995) ao discutir os “círculos viciosos da corrupção", se o clientelismo pode favorecer a corrupção, esta última também pode favorecer as práticas clientelistas. Isso ocorre quando os recursos obtidos de forma irregular - cobrança de comissões para liberação de recursos, desvio de recursos transferidos para prefeituras e entidades, e financiamento das campanhas por empresas além dos limites legais, por exemplo - são investidos no próprio circuito político por meio da distribuição de favores e compra de apoio. Uma vez que a concessão desses favores interfere na reputação do político, o fato de dispor desses recursos pode, portanto, colocar determinados candidatos em melhores condições de concorrência pelos cargos.

\section{Considerações finais}

A atuação dos parlamentares orientada para a liberação de recursos federais inscreve-se, portanto, num sistema complexo de relações de dependências mútuas e assimétricas, constituído, entre outros, por representantes dos poderes locais (estados e municípios), nacional (governo federal) e agentes privados. A extensão e a força das relações associadas ao atendimento das demandas por verbas originadas das localidades decorrem, em grande medida, dos distintos interesses que são capazes de articular. Porém, se as ações voltadas para a concessão de favores e recursos mobilizam e são legitimadas por esses distintos agentes sociais, elas, todavia, não mobilizam ou são legitimadas do mesmo modo, uma vez que seus interesses estão relacionados à posição que cada agente ocupa nesse sistema de relações sociais.

Quando mencionados nos estudos sobre o Poder Legislativo e Executivo, os favores e serviços prestados aos eleitores, os vínculos de lealdade, os esforços efetuados para a liberação de recursos para os municípios, as trocas de favores entre os parlamentares e as negociações envolvendo o apoio desses últimos ao governo são aspectos considerados apenas marginalmente - quando não são rotulados de clientelismo, fisiologismo ou corrupção. $\mathrm{O}$ argumento de que esses elementos são secundários não se sustenta, porém, quando se observa as diferentes áreas governamentais, instituições e domínios políticos nos quais eles se fazem presentes e operam. Examinar essas práticas em sua positividade, isto é, evitar um discurso apenas negativo em relação às mesmas, o que é compreensível em certa medida devido à influência das teorias modernizantes, pode ajudar-nos a perceber o modo como as trocas de serviços e benefícios materiais, sob a forma de favores, e as relações de dependência pessoal estruturam as relações políticas e definem um modo específico de operar do Estado. 
A troca de favores, serviços e os esforços efetuados para a obtenção de recursos federais é algo que não escapa à observação de vários autores que desenvolvem análises sobre a política no Brasil, em particular, e em outros países (Viana, [1920] 1973; Leal, 1975; Queiroz, 1976; Martins, 1994; Médard, 1981 e Thompson, 1995). ${ }^{22}$ Ressalte-se, no entanto, que se esses elementos são destacados quando se analisa a política local, eles não têm sido incorporados às análises efetuadas sobre a grande política. Dito de outro modo, os favores e serviços e as relações nas quais eles se sustentam e que são constituídas a partir deles, não são tratados como elementos centrais da política realizada a partir das instituições nacionais.

$\mathrm{O}$ peso dos compromissos e das relações de dependência pessoal criado e mantido por meio das trocas de favores, serviços, apoio político e recursos na grande política, por exemplo, pode ser percebido quando se tem em mente as medidas e decisões administrativas e governamentais nas quais estão fundadas essas práticas e relações. É o caso, entre outros, da aprovação de projetos governamentais e mudanças constitucionais que necessitam da aprovação dos parlamentares, do prestígio dos deputados e senadores nas localidades que representam, do funcionamento da burocracia governamental sujeita às pressões de políticos e agentes a eles vinculados (assessores, escritórios de consultoria e empreiteiras, por exemplo) e da apropriação ilícita dos recursos federais. Esses, portanto, não são aspectos menores quando se pensa sobre o funcionamento do Estado e sua relação com a sociedade. Além disso, ao mobilizar-se para atender aos pleitos, para o parlamentar, não está em jogo, como enfatiza a literatura sobre clientelismo político, somente a formação de clientelas eleitorais, mas o exercício de uma certa concepção específica sobre a representação parlamentar.

Esses diferentes interesses e relações se articulam, e ao mesmo tempo são justificados, a partir da referência à atuação dos parlamentares em favor de suas bases eleitorais. Compreende-se melhor a legitimidade que a menção às bases atribui às distintas condutas, quando se considera que à mesma está relacionada uma concepção específica sobre a representação política. $O$ fato dessa concepção ser partilhada por diferentes agentes sociais (prefeitos, funcionários e autoridades governamentais, entre outros) explica em grande medida a força social que possuem as condutas fundadas na referência às bases eleitorais. Entretanto, quando se considera mais detidamente o que significa a base, constata-se que a categoria remete a diferentes realidades: estado, municípios, população, comunidades, bairro, grupos que apóiam, locais onde se obtém votação e eleitores, entre outras. Ela, portanto, não é uma categoria precisa ou fixa. Essa propriedade da categoria permite que seja aplicada a diferentes situações. Por conseguinte, a importância dos estados e municípios na concepção da representação parlamentar e a flexibilidade da categoria fazem com que esta seja 
acionada para legitimar várias ações e justificar a conduta dos agentes em diferentes circunstâncias.

Essas condutas demonstram, por sua vez, de que forma a atuação dos parlamentares nas instituições nacionais é marcada por seus laços locais. São exemplos de como os interesses locais se fazem presente nas instituições nacionais.

Considerar o conjunto de práticas e relações associadas à atuação parlamentar dirigida para a obtenção de recursos para os estados e municípios que representam, faz emergir outra imagem dos deputados e senadores. Estes não aparecem somente como porta-vozes de diferentes pontos de vista e interesses presentes na sociedade, elaboradores de leis ou fiscalizadores do Poder Executivo, mas, sobretudo, como mediadores de demandas locais e interesses relacionados às suas redes políticas.

Essa forma de atuação de deputados e senadores aponta, desse modo, para uma das possibilidades histórico-culturais de como a instituição da representação política se realiza em termos práticos. ${ }^{23}$ Nesse sentido, o destaque para o vínculo com os estados e municípios, o atendimento dos pedidos de recursos e a atuação fora do Congresso são elementos que conformam uma concepção específica a respeito da representação política que valoriza os vínculos locais, a concessão de benefícios particularísticos e o estabelecimento de relações em termos de dependência pessoal. No contexto dessas relações e concepções, a liberação de recursos federais por parte dos parlamentares aparece, enfim, como uma espécie de necessidade que se tornou virtude.

\section{Notas}

1 Este trabalho resume algumas das questões discutidas em Bezerra (1999). Baseia-se em trabalho de campo realizado em Brasília sobretudo no período de março a junho de 1996. A realização da pesquisa foi possível graças a uma bolsa do Programa de Apoio à Pesquisa em Administração Pública (PAP), convênio ENAP/CAPES. Nomes e outras propriedades sociais que permitam identificar os informantes foram suprimidos.

2 Para uma análise sobre a atuação dos parlamentares no Congresso, do ponto de vista de suas prerrogativas legislativas, ver, entre outros, Novaes (1994) e Figueiredo e Limongi (1994).

3 Um estudo sobre a atividade congressual dos deputados foi desenvolvido por Costa (1980). 
4 O significado do "tempo da política" para a ordenação da vida social foi analisado por Palmeira e Herédia (1993 e 1995).

5 O lado formal da atividade parlamentar tem sido examinado sobretudo por sociólogos e cientistas políticos. Curiosamente, no entanto, as ações que estão além dos marcos formais não têm recebido a mesma atenção. De outro modo, o lado efetivo da atuação parlamentar que não coincide com as atribuições oficiais não tem sido incorporado, por exemplo, às análises efetuadas sobre o Poder Legislativo ou o exercício da representação parlamentar. Para um balanço sobre os trabalhos que têm sido realizados sobretudo por cientistas políticos remeto particularmente a Lima Junior (1998).

6 Não realizei um levantamento sistemático para verificar quantos são os parlamentares que afirmam atuar desse modo ou a sua distribuição por partidos ou regiões a que pertencem. Proponho, no entanto, que essa não é uma prática exclusiva de membros de partidos ditos de direita (ou conservadores) ou de parlamentares eleitos por estados atrasados (ou pobres) como sugerem as formulações mais freqüentes. Mesmo no interior de partidos (de esquerda) que se posicionam publicamente contra essa forma de atuação parlamentar e eleitos por estados desenvolvidos (ricos) encontram-se parlamentares que, em nome de um certo pragmatismo, voltam-se para a busca de recursos para suas bases.

7 A literatura sobre patronagem e clientelismo é extensa. Para uma idéia a respeito das discussões sobre os dois conceitos e análises efetuadas a partir deles, consultar, entre outros, os textos reunidos em Gellner e Waterbury (1977), Schmidt (1977), Strickon e Greenfield (1972), Eisenstadt e Lemarchand (1981), Roniger e Guner-Ayata (1994) e artigos reunidos no número especial da International Political Science Review, v. 4, n. 4, 1981 .

A atuação dos parlamentares dirigida para o entendimento de demandas originadas de suas bases eleitorais são comumente objeto de críticas e qualificações negativas. De maneira geral, são rotuladas - por políticos, analistas e imprensa - como clientelistas e fisiológicas. Nesses casos, menos do que como categorias analíticas, os termos são utilizados em sentido pejorativo. Servem para caracterizar essas práticas como atrasadas, tradicionais e/ou oligárquicas. Essa apropriação e uso dos termos estão, no entanto, relacionados diretamente a uma linha de interpretação (identificada com as teorias modernizantes) dos fenômenos sociais conhecidos como patronagem e clientelismo. Como argumento a seguir, ao longo deste trabalho, as noções de patronagem e clientelismo são utilizadas como conceitos analíticos, não tendo, portanto, o sentido (de acusação e denúncias) que lhe é atribuído mais comumente nas disputas políticas. De outro modo, a utilização dessas noções não expressa um juízo de valor acerca das condutas examinadas, mas visa dar uma inteligibilidade às mesmas.

8 Um exemplo da presença desse tipo de interpretação em análises sobre o clientelismo no Brasil pode ser encontrado no artigo de José de Souza Martins intitulado "Clientelismo e corrupção no Brasil contemporâneo". Na introdução do livro, em uma passagem na qual o autor propõe uma interpretação sobre o Estado brasileiro, lê-se, por exemplo: "E Estado baseado em relações políticas extremamente atrasadas, como as do clientelismo e da dominação tradicional de base patrimonial, do oligarquismo. No Brasil, o atraso é um instrumento de poder" (1994: 13).

9 É essa perspectiva que parece estruturar, para citar apenas um exemplo de um estudo brasileiro, o artigo de Jorge A. Filho a respeito do clientelismo e a política no Brasil (Avelino Filho, 1994: 34). Atento à questão do clientelismo eleitoral, particularmente à eleição dos parlamentares, o autor observa que a "baixa institucionalização do sistema político" e a "fragilização dos partidos" introduzem um alto grau de "incerteza" na "competição política". Como sugere o autor, "a desmoralização dos partidos, as regras eleitorais que induzem à proliferação de legendas e candidatos e à competição individual, 
e a generalização do desencanto e do cinismo entre os eleitores tornam cada vez mais incerta qualquer perspectiva política de longo prazo". Esse quadro favorece a atuação individualizada dos parlamentares tanto em relação ao Executivo quanto às suas bases eleitorais. As relações clientelistas estabelecidas pelos parlamentares com suas bases eleitorais é concebida, portanto, como um mecanismo por meio do qual estes buscam minimizar as incertezas em relação às suas candidaturas.

10 A utilização do conceito de clientelismo - e noções correlatas como mandonismo e coronelismo - na análise das relações entre o poder local e o poder nacional no Brasil, é discutida por Carvalho (1997). Preocupado com as distorções e confusões estabelecidas em torno de conceitos como mandonismo, coronelismo, clientelismo, feudalismo e patrimonialismo, o autor procura restabelecer as distinções e a precisão dos conceitos. Observo, contudo, que o artigo não avança no sentido da construção do clientelismo como um objeto de investigação. Para uma análise sobre a introdução e utilização do conceito de clientelismo no Brasil, consultar Banck (1999).

11 A presença das relações do tipo clientelista em sistemas político-democráticos é discutida nos artigos reunidos por Roniger e Guner-Ayata (1994). A necessidade de se pensar nas relações de caráter pessoal como um dado das relações políticas contemporâneas no Brasil é defendida, por exemplo, por Bezerra $(1995,1999)$ e Gay $(1999)$.

12 A importância de se considerar o intervalo de tempo nas análises sobre as trocas de dons é ressaltada, por exemplo, por Bourdieu (1996b).

13 Um exame detalhado sobre a intervenção dos parlamentares na elaboração do projeto de lei orçamentária pode ser encontrado em Rocha (1997).

14 Em função das disputas entre os parlamentares decorrentees dos interesses em torno da destinação dos recursos e das disparidades em termos do número de emendas e do valor dos recursos aprovados por cada um deles, nos últimos anos, foi estabelecido um acordo informal pelo qual ficou acertado que todo parlamentar tem assegurado uma cota - entre 1,5 milhão e 2 milhões de reais - para destinar conforme suas preferências.

15 Sobre a natureza dessa intervenção ver Rocha (1997) e Bezerra (1999).

16 Para depoimentos nesse sentido ver Diniz (1982: 118 - 119).

17 A importância das relações pessoais, sobretudo com os hierarquicamente superiores, como uma forma de demonstração de poder social no Brasil é acentuada, entre outros, por DaMatta (1983 e 1987). Lembro também que a ligação com as autoridades governamentais tem um lugar central nas análises desenvolvidas por Graham (1997).

18 A fragilidade dos interesses puramente materiais como fundamento para a dominação é destacado por M.Weber ao discutir os tipos de dominação. Referindo-se à natureza dos motivos (costume, afetivos, materiais, ideais etc.) que define o tipo de dominação, esse autor observa que "Motivos puramente materiales y racionales con arreglo a fines como vínculo entre el imperante y su cuadro implican aquí, como en todas partes, una relación relativamente frágil" (1984: 170).

19 O encaminhamento de pedidos aos órgãos ministeriais é uma função historicamente associada ao desempenho do cargo. Analisando as correspondências recebidas por membros dos Gabinetes onde constam solicitações de nomeações, R. Graham — para ficarmos apenas em um exemplo - observa que "os mais freqüentes autores desses pedidos eram deputados e senadores que escreviam a membros de Gabinete em favor de terceiros. Escrever tais cartas era uma das principais atividades de um deputado" (1997: 272).

20 Ver, entre outros, Silverman (1977), Boissevain (1966) e Michaelson (1976).

21 Para uma análise da corrupção nesse sentido ver Bezerra (1995 e 1999).

22 Sobre esse assunto, consultar ainda a literatura sobre pork-barrel. Ver, por exemplo, Ellwood e Patashnick (1993), Stein e Bichers (1994) e Evans (1994). 
23 Referindo-se ao Brasil e às eleições no século XIX, R. Graham aponta para a questão da introdução do sistema representativo no Brasil ao observar, por exemplo, que "o governo representativo não era uma herança dos tempos coloniais, mas uma exótica ideologia importada; e os princípios democráticos não se ajustavam à estratificada sociedade brasileira, (...)" (1997: 105). Baseado em dados recentes sobre como o voto é percebido por populações rurais, M. Palmeira observa — chamando atenção para o modo como este é objeto de uma apropriação histórico-cultural particular — que nessas circunstâncias o voto tem o "significado de uma adesão". Assim, "para o eleitor, o que está em pauta em uma eleição não é escolher representantes, mas situar-se de um lado da sociedade" (1992: 27).

\section{|| Referências bibliográficas}

Ames, Barry. (1995), "Electoral rules, constituency pressures, and pork-barrel: bases for voting in the Brazilian congress". The Journal of Politics, v.57, n. 2.

Avelino Filho, G. (1994), "Clientelismo e política no Brasil. Revisitando velhos problemas". Novos Estudos CEBRAP, n. 38.

BANCK, Geert A. (1999), "Clientelism and Brazilian political process: production and consumption of a problematic concept", in Nas, Peter J. M.; Silva, P. (ed.), Modernization, Leadership, and Participation. Netherlands: Leiden University Press.

BezerRa, Marcos O. (1995), Corrupção. Um estudo sobre poder público e relações pessoais no Brasil. Rio de Janeiro: ANPOCS/Relume-Dumará.

. (1999), Em nome das "bases". Política, favor e dependência pessoal.

RJ: NUAP/Relume-Dumará.

Boissevain, Jeremy. (1966), "Patronage in Sicily". MAN, 1(1), p. 18-33.

Bourdieu, Pierre. (1976), "Les modes de domination". Actes de la Recherche en Sciences Sociales, n. 2/3.

. (1989), "A representação política. Elementos para uma teoria do campo político", in O Poder simbólico. Lisboa/Rio de Janeiro: DIFEL/Bertrans Brasil. . (1996), "Espírito de Estado. Gênese e estrutura do campo burocrático", in Razões Práticas. Sobre a teoria da ação. Campinas: Papirus.

(1996), "Marginália. Algumas notas adicionais sobre o dom”.Mana.

Estudos de antropologia social, v. 2, n. 2.

Cartier-Bresson, J. (1992), "Éléments d'analyse pour une économie de la corruption". Revue Tiers Monde, t. XXXIII, n. 131, jui-sep.

Carvalho, José M. (1997), "Mandonismo, coronelismo, clientelismo: uma discussão conceitual”. Dados, v. 40, n. 2.

Costa, Maria Cecília S. da. (1980), "Os caminhos da casa”. Dissertação de mestrado. Rio de Janeiro: PPGAS/MN/UFRJ.

DAM ATTA, Roberto. (1983), Carnavais, malandros e heróis. 4a ed. Rio de Janeiro: Zahar Editores.

. (1987), "Cidadania: a questão da cidadania num universo relacional”, in A casa e a rua. Rio de Janeiro: Guanabara. 
Della Porta, D. (1995), "Les cercles vicieux de la corruption”, in Della Porta, D., Mény, Y. Démocratie et corruption en Europe. Paris: La Découverte.

Dinız, Eli. (1982), Voto e máquina política. Patronagem e clientelismo no Rio de Janeiro. Rio de Janeiro: Paz e Terra.

Eisenstadt, S. N., Lemarchand. (1980), Political clientelism, patronage and development. London: Sage Publications.

Elias, Norbet. (1980), Introdução à Sociologia. Lisboa: Edições 70.

Ellwood, J., Patashnich, E. (1993), "In praibe of pork”. Public Interest, n. 110.

Evans, Diana. (1994), "Policy and pork: the use os pork-barrel projects to build policy coalitions in the house of representatives". American Journal of political science, v. 38, n. 4.

Figueiredo, Argelina C., Limongi, Fernando. (1994), "O processo legislativo e a produção legal no Congresso pós-constituinte". Novos Estudos CEBRAP, n. 38.

FinLey, M. I. (1985), A política no mundo antigo. Rio de Janeiro: Zahar.

Foster, G. M. (1967), "The dyadic contract: a model for the social structure of a mexican peasant village", in PоттеR, J. M. (ed.), Peasant society: a reader. Boston: Little, Brown.

Geddes, B., Neto, A. R. (1992), "Institutional sources of corruption in Brazil". Third World Quartely, v. 13, n. 4.

Gellner, E., Waterbury (ed.). (1977), Patrons and clients in mediterranean societies. London: Duckworth.

Graham, Richard. (1997), Clientelismo e política no Brasil do século XIX. Rio de Janeiro: UFRJ.

Guy, Robert. (1998), "Rethinking clientelism: demands, discourses and practices in contemporary Brazil", in European Review of Latin American and Caribbean Studies, n. 65 , dec.

Landé, Carl. (1977), "Introduction: the dyadic basis of clientelism”, in Schmidt, S. W.etal (ed.) Friends, Followers, and factions. Berkeley: University of California Press.

LEACH, Edmund. (1989) "Dívidas, relações, poder", in A diversidade da antropologia. Lisboa: Edições 70.

Leal, Victor N. (1975), Coronelismo, enxada e voto. São Paulo: Alfa-Omega.

Lima Júnior, Olavo B. (1997), Instituições Políticas Democráticas. O segredo da legitimidade. Rio de Janeiro: Jorge Zahar Editor.

(1998), Participação eleitoral; sistemas eleitorais e sistemas partidários; o legislativo e suas relações com o Executivo — um balanço da produção. Mimeo.

Little, W., Posada-Carbó, E. (1996), "Introduction", in Little, W.; Posada-Carbó, E., (ed.), Political Corruption in Europe and Latin America (Institute of Latin American Studies Series). London: Macmillan Press.

Martins, José de S. (1994) "Clientelismo e corrupção no Brasil contemporâneo", in $O$ poder do atraso. São Paulo: Hucitec.

M auss, Marcel. (1974), "Ensaio sobre a dádiva. Forma e razão da troca nas sociedades arcaicas", in Sociologia e antropologia, v. 2. São Paulo: EPU/EDUSP.

(1974), "Esboço de uma teoria geral da magia", in Sociologia e antropologia, v. 2. São Paulo: EPU/EDUSP.

MÉDARD, Jean-François. (1981), "Political clientelism in France: the center-periphery nexus reexamined", in Eisenstadt, S. N., Lemarchand. Political clientelism, patronage and development. London: Sage Publications.

Mény, Yves. (1992), La corruption de la République. Paris: Fayard.

Michaelson, Karen L. (1976), "Patronage, mediators, and the historical context of social organization in Bombay". American Ethnologist, v. 3, n. 2. 
M InTZ, Sidney. (1967), "Pratik: Haitian Personal Economic Relationships”, in Potтer, J. M., (ed.), Peasant society: a reader. Boston: Little, Brown.

Novaes, Carlos A. M. (1994), "Dinâmica institucional da representação". Novos Estudos CEBRAP, n. 38.

Palmeira, Moacir. (1996), “Política, facções e voto”, in Palmeira, M., Goldman, M. (org), Antropologia, voto e representação política. Rio de Janeiro: Contra Capa. (1998), Poder Local. Rio de Janeiro: PPGAS/MN/UFRJ. Mimeo.

Palmeira, M., Heredia, B. (1993), "Le temps de la politique”. Études Rurales, jui-dec. . (1995), "Os comícios e a política de facções". Anuário Antropológico/94.

Pitt-Rivers, Julian. (1971), The people of Sierra, $2^{\mathrm{a}}$ ed. Chicago: The University of Chicago Press.

Queiroz, Maria I. P. de. (1976), O mandonismo local na vida política brasileira e outros ensaios. São Paulo: Alfa-Omega.

Rосна, Paulo. (1997), “Congresso Nacional e Orçamento Público. O processo decisório da fase legislativa do ciclo orçamentário ampliado". Dissertação de mestrado. Brasília: UNB.

Roniger, L., Günes-Ayata, A. (1994), Democracy, clientelism, and Civil Society. Colorado: Lynne Rienner Publishers.

SснміDт, S. W., et al (ed.).(1977), Friends, followers, and factions. Berkeley: University of California Press.

Sсотт, J. (1969), "Corruption, machine politics and political change". American Political Science Review, LXVI.

Silverman, Sydel F. (1977), "Patronage and community-nation relationships in Central Italy", in SснміDт, S. W., etal (ed.), Friends, followers, and factions. Berkeley: University of California Press.

Stein, R., Bickers, K. (1994), "Congressional elections and the pork-barrel”. Journal of politics, v. 56, n. 2.

Strickon, A., Greenfield, S. (1972), Structure and Process in Latin America. Patronage, Clientage and Power Systems. Albuquerque: University of New Mexico Press.

Tномpson, D. F. (1995), Ethics in Congress. From individual to institutional corruption. Washington: The Brookings Institution.

Vianna, Oliveira. (1973), Populações Meridionais do Brasil. Rio de Janeiro: Paz e Terra/ UFF, v. 1.

Weber, Max. (1984), Economia y Sociedad. 2a ed., (7ª reimpresión). México: Fondo de Cultura Económica.

Wolf, Eric R. (1966), "Kinship, friendship and patron-client relations in complex societies", in Banton, M., (ed.), The social anthropology of complex societies. London: Tavistock. 


\section{Representação política e acesso aos recursos federais \\ Marcos Otavio Bezerra}

$\mathrm{O}$ trabalho focaliza as relações, práticas e interesses articulados em torno da atuação efetiva de parlamentares do Congresso brasileiro, orientada para a obtenção de recursos federais para suas bases eleitorais. A análise é construída a partir da participação de deputados e senadores no processo de elaboração e execução do orçamento da União. Procura descrever e analisar esta forma de atuação no contexto das relações de dependência recíproca, mas assimétrica, que vinculam parlamentares, prefeitos, autoridades governamentais e agentes privados. Argumenta que essa conduta dos parlamentares está relacionada a uma certa concepção específica a respeito da representação parlamentar. Mostra como a referência às bases está presente em diferentes planos de ação social e é associada a um conjunto de ações cotidianas concebidas como legítimas, mas também ações tidas como ilícitas. O trabalho propõe que o cálculo eleitoral é uma dimensão do fenômeno investigado, assim como a busca de prestígio, o atendimento de expectativas e o cumprimento de obrigações sociais relacionadas ao desempenho parlamentar.

\section{Representación política e acceso a los recursos federales \\ Marcos Otavio Bezerra}

El trabajo enfoca las relaciones, prácticas e intereses articulados alrededor de la actuación de parlamentares del Congreso brasileño destinada a obtener recursos financieros federales para sus bases electorales. El análisis se construye a partir de la participación de diputados y senadores en el proceso de elaboración y ejecución del presupuesto de la Unión. Se procura describir y analizar esta forma de actuación en el contexto de las relaciones de dependencia recíproca y asimétrica, que vinculan parlamentares, prefectos, autoridades gobernamentales y agentes del sector privado. El autor argumenta que esta conducta de los parlamentares guarda relación com una cierta concepción de lo que es la representación parlamentar. Muestra de que forma la referencia a las bases está presente en diferentes planos de acción social y está asociada a un conjunto de acciones cotidianas concebidas como legítimas, pero también a acciones consideradas ilícitas. El trabajo postula que el cálculo electoral es una dimensión del fenómeno investigado, tanto como la búsqueda de prestigio, la satisfacción de las expectativas y el cumplimiento de las obligaciones sociales relacionadas al desempeño parlamentar.

\section{Political representation and access to federal resources \\ Marcos Otavio Bezerra}

This work focuses on the relationships, practices and interests connected to the activities of parliamentary representatives in the Brazilian Congress, as they seek federal resources for their electoral basis (bases eleitorais). The participation of deputies and senators in the elaboration and execution of the Union's annual budget is analyzed. This form of parliamentary activity is described and analyzed in the context of the relations of mutual and asymmetrical dependency that link congressmen, mayors, government authorities and private agents. The author argues that the congressmen's behavior is related to a conception of parliamentary representation. The work shows that reference to the electoral basis is present in various plans of social action, and that it is associated both to a set of routine actions seen as legitimate and to acts that are considered illicit. The work suggests that electoral calculations constitute a dimension of the phenomenon investigated, as well as the search for prestige, the attention to expectations, and the social obligations connected to parliamentary performance.

Revista do

Serviço

Público

Ano 51

Número 2

Abr-Jun 2000

Marcos Otavio

Bezerra é

professor do

Departamento

de Sociologia

da Universidade

Federal

Fluminense

(UFF),

pesquisador

do Núcleo de

Antropologia

da Política

(NuAP), mestre

e doutor em

antropologia

social pelo

PPGAS/MN/

UFRJ 